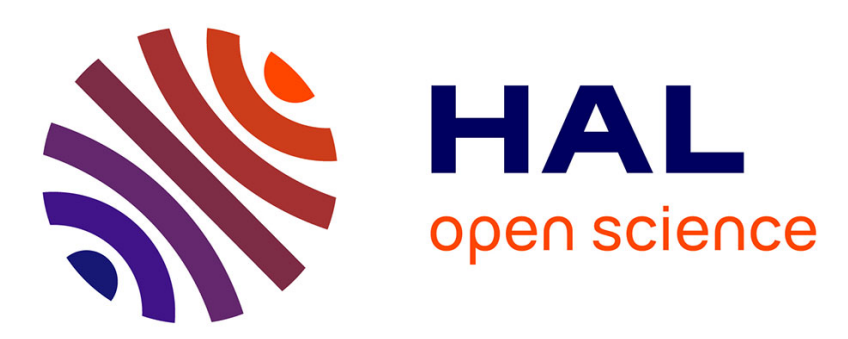

\title{
Structural characterisation of corrosion products on archaeological iron. An integrated analytical approach to establish corrosion forms
}

Delphine D. Neff, Solenn Reguer, Ludovic Bellot-Gurlet, Philippe Dillmann, Régis Bertholon

\section{To cite this version:}

Delphine D. Neff, Solenn Reguer, Ludovic Bellot-Gurlet, Philippe Dillmann, Régis Bertholon. Structural characterisation of corrosion products on archaeological iron. An integrated analytical approach to establish corrosion forms. Journal of Raman Spectroscopy, 2004, 35 (8-9), pp.739-745. 10.1002/jrs.1130 . hal-00315905

\section{HAL Id: hal-00315905 \\ https://hal.science/hal-00315905}

Submitted on 2 Sep 2008

HAL is a multi-disciplinary open access archive for the deposit and dissemination of scientific research documents, whether they are published or not. The documents may come from teaching and research institutions in France or abroad, or from public or private research centers.
L'archive ouverte pluridisciplinaire $\mathbf{H A L}$, est destinée au dépôt et à la diffusion de documents scientifiques de niveau recherche, publiés ou non, émanant des établissements d'enseignement et de recherche français ou étrangers, des laboratoires publics ou privés. 


\title{
Structural characterisation of corrosion products on archaeological iron. An integrated analytical approach to establish corrosion forms
}

\author{
Delphine Neff ${ }^{1}$, Solenn Reguer ${ }^{1}$, Ludovic Bellot-Gurlet ${ }^{2}$, Philippe Dillmann ${ }^{3}$ and Régis Bertholon ${ }^{4}$ \\ ${ }^{1}$ CEA and ANDRA, Laboratoire Pierre Süe, CEA Saclay 91191 Gif-sur-Yvette Cedex, France, Neff@drecam.cea.fr and \\ Reguer@drecam.cea.fr \\ ${ }^{2}$ Laboratoire de Dynamique Interactions et Réactivité (LADIR), UMR 7075 CNRS and Université Pierre et Marie Curie Paris VI, 2 rue \\ Henri Dunant, 94320 Thiais, France, Bellot-Gurlet@glvt-cnrs.fr \\ ${ }^{3}$ LRC CEA DSM 01-27 : CNRS IRAMAT UMR5060, IPSE, Laboratoire Pierre Süe, CEA Saclay 91191 Gif-sur-Yvette Cedex, France, \\ Dillman@drecam.cea.fr \\ ${ }^{4}$ Section Conservation et Restauration des Biens Culturels, UFR 03, Université Paris 1 Panthéon-Sorbonne, 17 rue de Tolbiac, 75013 , \\ Paris, France, Regis.Bertholon@univ-paris1.fr
}

\begin{abstract}
The description and identification of corrosion products formed on archaeological iron artefacts needs various approaches at different observation scales. For this study, samples of five different sites were prepared using two techniques. The first one consists in cutting cross sections perpendicular to corrosion layers. This allows local observations and analysis of the corrosion layer stratigraphy at different levels. The second one consists in performing manual grinding or abrading of the corrosion layers starting from the current surface of the excavated artefact to the metal core. It allows the description of the successive layers and is well adapted for the analysis on a larger scale. In addition to these two observation scales, the identification of the iron oxides formed needs the coupling of several complementary techniques. Elementary compositions were determined by SEMEDX and Electron Micro-Probe Analysis (EMPA). Structural identification was performed by X-ray micro Diffraction under synchrotron radiation ( $\mu$ XRD) and micro Raman spectroscopy. These analyses were performed on the same samples both with X-ray diffraction and Raman spectroscopy in order to ensure a reliable characterisation. In some cases there are some ambiguities or overlapping between signatures of different phases by micro X-rays diffraction (as maghemite/magnetite) or Raman spectroscopy (as goethite/magnetite) which can be raised by the association of the two methods. The final aim is to set up an analytical methodology that will be the best for the study of ancient iron corrosion products. It is the first step of the study of long term mechanisms of iron in soil.
\end{abstract}

KEYWORDS: Raman micro-spectroscopy, synchrotron X-Rays micro-diffraction, iron oxides and oxy-hydroxides, archaeological artefact, corrosion typologies

\section{INTRODUCTION}

Archaeological iron artefacts undergo corrosion phenomenon during their burial period and also after excavation. These degradations can lead to a dramatic state of certain objects and in consequence information about their function or forging treatments could be lost. Though it is important to increase the knowledge on long term corrosion mechanisms in order to restore the excavated objects and prevent their further deterioration. The aim of this paper is to present a global study dedicated to the determination of corrosion forms on five different archaeological sites. This paper will focus on the presentation of the Raman microspectroscopy analytical contribution to point out its complementarity with other techniques also employed in this study to give structural information at the microscopic scale. 


\section{Corrosion of archaeological artefacts}

Up to now, the corrosion of this kind of artefacts in soil has been studied for different purposes and some of them are reviewed here. On one hand some authors $^{1-4}$ consider archaeological artefacts as analogues for the estimation of iron corrosion behaviour in soil, particularly for obtaining average corrosion rates. Unfortunately, these studies rarely give detailed analysis of the corrosion products. On the other hand other kind of studies provides information for preventing degradation after excavation and ensuring reliable restoration. These recent ones aimed at the understanding of the corrosion phenomenon in the field of conservation of archaeological artefacts. Soerensen et al. ${ }^{5}$ underline the difficulty of this kind of work. Soil is in fact a complex environment and different parameters as geological factors (soil types, $\mathrm{pH}$ and electrical resistivity), hydrological factors (water flow through ground layers) and soil chemical composition play a role in the corrosion process. Gerwin et al. ${ }^{6}$ worked on iron nails and measured the degree of corrosion by comparing the size of the metal core remaining with that of the object before corrosion estimated from $X-$ ray photograph. This method is not very precise because of the difficulty in determining the original size. Nevertheless the obtained results show general tendencies about the influence of soil composition on iron corrosion rates. For example, phosphates and specially carbonates lead to the formation of a protective layer on the metal that slows down the corrosion process, but the phases constituting this layer were not specified in this study. Conversely, a high sulphates or chlorides content in soil water ensures the destruction of layers covering the metallic substrate that would have been protective. To estimate corrosion rates, two simulation studies have been carried out on steel buried in soil. Angelini et al. ${ }^{7}$ studied a soil with a high content of organic matter and carbonates. These authors showed that the sample corrosion rate decreases with burial time (from $0.035 \mathrm{~g} / \mathrm{dm}^{2} /$ day after 30 days to 0.028 $\mathrm{g} / \mathrm{dm}^{2} /$ day after 120 days). To complete these observations X-ray Diffraction (XRD) and Fourier Transform Infrared Spectroscopy (FT-IR) data were collected in order to identify the corrosion layers. They report the presence of goethite $(\alpha-\mathrm{FeOOH})$, akaganeite $(\beta-\mathrm{FeOOH})$ an oxyhydroxide containing chloride, magnetite $\left(\mathrm{Fe}_{3} \mathrm{O}_{4}\right)$ and siderite $\left(\mathrm{FeCO}_{3}\right)$ in the corrosion products. Fell et al. ${ }^{8}$ analysed archaeological artefacts excavated from a waterlogged deposit. This particular environment leads to the formation of aggregates of sulphides, identified by XRD. These phases are formed principally through biological activity. On some samples the major corrosion product was siderite: it is assumed that this phase is often associated with sulphides. Some studies were specifically dedicated to the understanding of the long term corrosion behaviour of archaeological iron artefacts in clay soils. Pons et al.9,10 performed Raman microspectroscopy analyses on cross sections of about ten corroded archaeological iron artefacts dated from the beginning of the $X X^{\text {th }}$ century and coming from the same site. These analyses reveal the presence of goethite and magnetite as main corrosion products. Moreover, some electrochemical measurements on these artefacts show that the internal zone of the corrosion products seems to be less porous than the external one.

\section{The limit of the original surface}

To find the original shape of archaeological artefacts, Bertholon ${ }^{11,12}$ worked on the concept of original surface (OS). The author defined the original surface as the artefact's surface at the time of its burial or abandonment, that means before the beginning of the corrosion process. When the artefact has corroded, its surface has changed but it is still possible to locate the limit of the original surface (also named limitos) within the present corroded materials. The limitos is the limit between different materials that constituted the object (metal, mineral and organic parts) and the surrounding soils at the time of the abandonment. Then it is expected to find special features in the artefact's corrosion layers regarding their position to the limit of the original surface. Corrosion layers located under the limitos are recognisable because they contain "inner markers" coming out from the metallic substrate (slag inclusions for example), and those located above the limitos by the presence of "outer markers", such as soil minerals (quartz grains...). The limit of the original surface does not always coincide with the level of the original surface of the object because it can move during the formation of oxide scales.

When examining the artefact prior to treatment, conservators carefully abrade the corrosion layers under binoculars by manual mechanical means (scalpels, needles, micro-grinding wheels, microsandblasting, etc.). This limited drilling allows conservators to distinguish the main corrosion strata according to their nature (corrosion products, soil, deposit, metal, etc.) and physical characters (colour, hardness, compactness, porosity, etc.). Other strata characters such as shape, direction are described according to a new descriptive method of corrosion being currently perfected ${ }^{11,12}$.

\section{Aim of the study}

Considering this short review, all the studies on archaeological artefacts cited here are very dissimilar. It appears that literature data alone are not sufficient to provide a complete and statistical overview. Moreover, the fine and local determination of the corrosion products structure was rarely undertaken and it is important to obtain such data to understand the corrosion mechanisms. Two methods that allow the identification of the structure at micrometric scale are the synchrotron X-ray micro diffraction $(\mu \mathrm{XRD})$ and the Raman microspectroscopy ( $\mu$ Raman): they were employed to study the iron corrosion during long period. The aim was to collect information on the corrosion phenomenon by analysing a large number of corroded 
artefacts. To this purpose, the corrosion products of about forty archaeological artefacts were analysed. First, Neff et al. ${ }^{13}$ proceed to a local characterisation of the corrosion products of 9 artefacts coming from 3 different sites aged of 500, 600 and 800 years by micro $X$ Ray diffraction $(\mu \mathrm{XRD})^{14}$. In this study, the analytical approach, including composition and structure analysis by Raman micro spectroscopy, was specially established to study statistically significant series. Moreover, two complementary preparation techniques of the samples were tested on the artefacts: on one hand analyses on cross sections and on the other hand, stratigraphic probes by mechanical abrasion were performed. This conducts to propose an analytical methodology for corrosion product analyses on iron archaeological artefacts, using different characterisation techniques.

\section{EXPERIMENTAL PROCEDURE}

\section{Instrumentation}

First, the optical microscope was used to study the metallographic structure of the iron core and to observe the morphology of the corrosion products. Then, composition analyses were performed on the samples by Energy Dispersive Spectroscopy (EDS) coupled to a Scanning Electron Microscope (SEM). The analyses were done under an accelerating voltage of $15 \mathrm{kV}$. The $\mathrm{Si}(\mathrm{Li})$ detector used was equipped with a thin beryllium window that allows to detect and quantify oxygen with a good accuracy (about 1\% relative error on iron oxides standards). The EDS analyses performed here can not quantify light elements as carbon and gives only relative analyses. In the case of the presence of carbonates, composition analyses were done by Electron Probe MicroAnalysis (EPMA) which provides absolute composition data. EPMA was performed with a $2 \times 2 \mu m^{2}$ beam accelerated under $15 \mathrm{kV}$.

The local structure was determined by $\mu$ XRD. These experiments were performed on the D15 beamline at the Laboratoire pour l'Utilisation $d u$ Rayonnement Synchrotron (LURE) at Orsay (France). The set-up was described elsewhere ${ }^{12,15,16}$. A microbeam of $20 \times 20 \mu \mathrm{m}^{2}(\lambda=0.08857 \mathrm{~nm})$ was focused on thin films made from the cross sections. The advantage of this method is the disposability of reference spectra which are collected in the JCPDF databank. Meanwhile the access to the beamline is not easy and the sample preparation in thin sections $(\sim 30 \mu \mathrm{m})$ is delicate.

The $\mu$ Raman was employed because it ensures a great facility of use. Measurements were performed at Laboratoire de Dynamique Interaction et Réactivité (LADIR) with a Notch-based spectrometer LabRam Infinity (Jobin Yvon-Horiba) using the radiation at 532 $\mathrm{nm}$ of a frequency-doubled Nd:YAG laser. Samples were observed under an Olympus microscope with Leitz objectives 10x, and long-focus 50x and 100x. With the 100x objective the diameter of the analysed area is about $3 \mu \mathrm{m}$. A Peltier-based cooled CCD records spectrum and the resolution given by the spectrometer setting is around $2 \mathrm{~cm}^{-1}$. As some iron oxides, particularly magnetite, are highly sensitive to laser irradiation we use a set of six density filters to modulate the laser power on the sample from $5.2 \mathrm{~mW}$ to $5 \mu \mathrm{W}$. Acquisition and basic treatment of spectra are made with the LabSpec (Jobin Yvon-Horiba) software. The sample table is motorised which allows to collect profile and spectral cartography in automatic acquisition mode.

\section{Methodology}

Five French excavation sites were chosen because of their differences of dating and soil. From these sites about forty archaeological artefacts were studied (Table 1).

Table 1. Archaeological French sites where samples were taken

\begin{tabular}{|c|c|c|c|c|}
\hline Site & Dating & Location & $\begin{array}{c}\text { Number } \\
\text { of studied } \\
\text { artefacts }\end{array}$ & $\begin{array}{c}\text { Analytical } \\
\text { approach }\end{array}$ \\
\hline Cabaret & $12-13^{\text {th }} \mathrm{c}$ AD & $\begin{array}{c}\text { Around Carcassonne } \\
\text { (Aude) }\end{array}$ & 15 & Cross section \\
\hline Montbaron & $12-13^{\text {th }} \mathrm{c}$ AD & $\begin{array}{c}\text { Around Chateauroux } \\
\text { (Indre et Loire) }\end{array}$ & 6 & Cross section \\
\hline Avrilly & $15^{\text {th }} \mathrm{c}$ AD & $\begin{array}{c}\text { Around Chartres } \\
\text { (Eure) }\end{array}$ & 8 & Cross section \\
\hline Glinet & $16^{\text {th }} \mathrm{c}$ AD & $\begin{array}{c}\text { Around Rouen } \\
\text { (Seine Maritime) }\end{array}$ & 8 & Cross section \\
\hline $\begin{array}{l}\text { Saint- } \\
\text { Denis }\end{array}$ & $10-11^{\text {th }} \mathrm{c}$. AD & Around Paris & 1 & $\begin{array}{c}\text { Stratigraphic } \\
\text { probing }\end{array}$ \\
\hline probing \\
\hline
\end{tabular}

In order to analyse the entire system constituted by the iron core and the burial environment, artefacts were collected with adhering soil. Samples were dried in an oven to withdraw the water and were mounted in epoxy resin.

As said before, two different preparation techniques were tested on the samples:

\section{Cross sections analyses}

Cross sections were cut into each of them. After polishing the samples with diamond paste ( 3 et $1 \mu \mathrm{m})$, all the techniques (especially $\mu$ Raman) were used to locally determine the morphology, the composition and the structure of the corrosion products on the cross section. For each artefacts, the same cross section was used for all the techniques except for the X-ray microdiffraction which required a specific preparation: a cross section is cut in the artefact and polished until having a thickness of maximum $50 \mu \mathrm{m}$ because the acquisitions are done in transmission mode.

Stratigraphic probe

This investigation method is applied to non-cut artefacts. Locally on the object, a mechanical abrasion is used to make a stratigraphic probing. It is then possible to collect $\mu$ Raman spectra from these different zones. 


\section{Raman characterisation of iron oxides and oxy- hydroxides}

Various reference spectra are available in literature dealing with corrosion or mineralogy, for instance concerning iron oxides and oxy-hydroxides ${ }^{17-28}$ and for carbonate ${ }^{9,29-33}$. But, as no certified database of Raman spectra exists, we also acquire with our experimental set-up some spectra collected on commercial products or laboratory synthesised samples. A powder of goethite $(\alpha-\mathrm{FeOOH})$ has been synthesised by us following the instructions given by Schwertmann ${ }^{34}$ and was controlled by X-Ray Diffraction by us. After synthesis, the composition analysis show that a low amount of $\mathrm{K}$ (several thousand ppm) remains in the $\mathrm{FeOOH}$ structure. This element, initially present in a product used for the synthesis ( $\mathrm{KOH}$ solution), could be in insertion in the lattice. Nevertheless it have no detectable influence on the XRD spectra compared to the JCPDF reference. The $\mu$ Raman spectrum is shown on Figure 1a. The main peak is localised at $388 \mathrm{~cm}^{-1}$ and other major peaks appear at 301, 416 and $685 \mathrm{~cm}^{-1}$. This last one is larger than the peak generally mentioned on reference spectra in a previous paper ${ }^{25}$. This could be due to the presence of potassium.
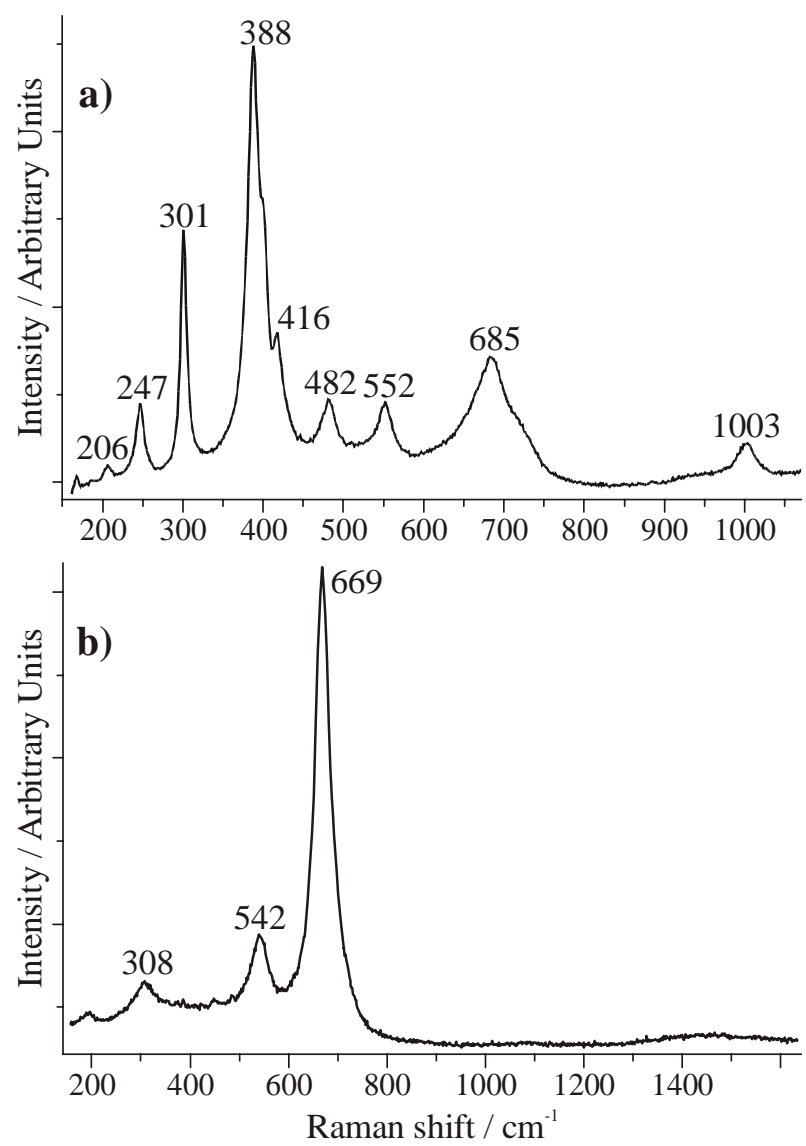

Figure 1. a) Goethite spectrum, long focus x100, laser power $0.21 \mathrm{~mW}, 600 \mathrm{~s} \times 2$ 2accumulations; b) Magnetite spectrum, long focus $x 100$, laser power $0.06 \mathrm{~mW}, 1 \mathrm{~h}$

A Merck Puratronic magnetite reference powder was analysed. The spectrum is shown on Figure $1 \mathrm{~b}$. The main peak has a Raman shift of $669 \mathrm{~cm}^{-1}$. Two other peaks are located respectively at 308 and
$542 \mathrm{~cm}^{-1}$. Some laser power stability tests have been performed on magnetite which leads to the formation of haematite above a laser power threshold as shown in Figure 2. According to literature ${ }^{25}$, magnetite can transform under heating conditions, first into maghemite at about $200^{\circ} \mathrm{C}$ and then haematite around $400^{\circ} \mathrm{C}$. Thus, a moderate laser power must be routinely used for iron corrosion product analysis and when a maghemite (or haematite) spectrum is obtained, a checking experiment with lowest power and a longer acquisition time at a different location in the same phase must be performed to ensure whether the maghemite is really present or is obtained by transformation of magnetite.

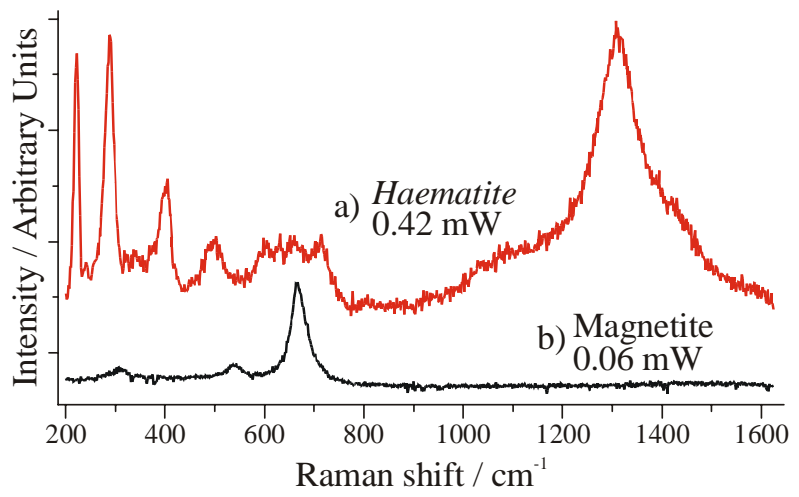

Figure 2. Two spectra of the same magnetite reference powder, a) $0.42 \mathrm{~mW}$, b) $0.06 \mathrm{~mW}$, acquisitions of $30 \mathrm{~s}$

Meanwhile, in some case it was not easy to discriminate the structure of some phases. For example, in this work the various carbonates were difficult to distinguish by $\mu$ Raman. Indeed, in corrosion products, especially when iron and calcium are present it is sometimes impossible to attribute the main Raman shift of carbonate to siderite $\left(\mathrm{FeCO}_{3}\right)$, calcite $\left(\mathrm{CaCO}_{3}\right)$ or a mix of these two phases. The main peak for these phases is assigned respectively to $1084 \mathrm{~cm}^{-1}$ and $1088 \mathrm{~cm}^{-1}$ for siderite and calcite ${ }^{33}$. In fact the bending modes (minor peaks) are more sensitive than the $v 1$ symmetric mode to discriminate these two phase but, in our samples the relatively low phase crystallinity does not allow the observation of these peaks. Moreover solid solutions of these carbonates are not well documented. For example, a profile was collected on a zone where only siderite was identified by $\mu$ XRD (it is important to note that, by this method, $\mathrm{FeCO}_{3}$ and $\mathrm{CaCO}_{3}$ can easily be discriminated). EDS analyses in the same zone show that this siderite can contain various amounts of Ca (from 1.5 to 2.3 mass $\%$ ). Figure 3 shows the shift of the siderite main peak from 1084 to $1088 \mathrm{~cm}^{-1}$ on different spectra collected at several points of this zone. This illustrates the necessity, when the detailed interpretation of Raman spectra is difficult, to use other complementary analytical techniques.

The last point to take into account when collecting Raman spectra, is the peak overlap. In the case of the iron corrosion products, this phenomenon occurs in the presence of goethite/magnetite mix. 


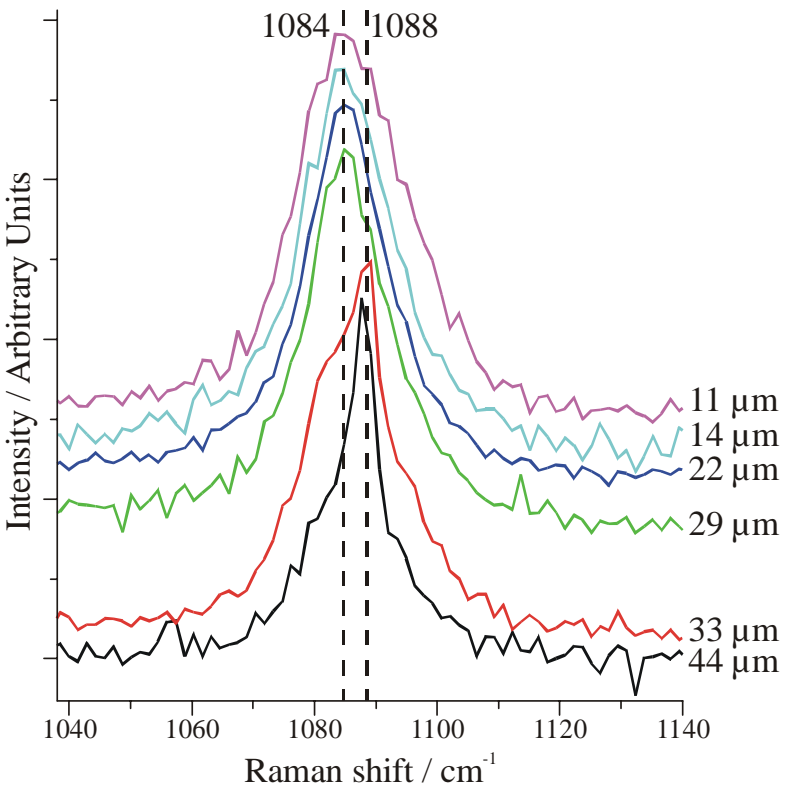

Figure 3. Raman shift of the siderite versus the distance to the interface metal/corrosion products (Cacontain increasing from 1.5 to $2.3 \mathrm{wt} \%$ ), sample GL 02 05, Glinet site

Figure 4 shows the difference of signal intensity for spectra collected in the same conditions on reference powders of these two phases. Peaks around $700 \mathrm{~cm}^{-1}$ are very close for these two phases. Moreover it is the main for magnetite. Thus, it can be difficult to clearly identify low quantity of magnetite in goethite. It is the same in the case of a small amount of magnetite in maghemite. These restrictions can be overcome by the crossed use of complementary methods as $\mu \mathrm{XRD}$.

As said before, $\mu \mathrm{XRD}$ was used to determine the structure of the corrosion products on archaeological samples. But, because this method is not so versatile, to increase the number of studied samples $\mu$ Raman proved to be the easiest to use technique. The advantage of $\mu$ XRD is the reference spectra that are available. But $\mu$ Raman is easy to utilise, though it allows prospecting quickly a high quantity of samples.

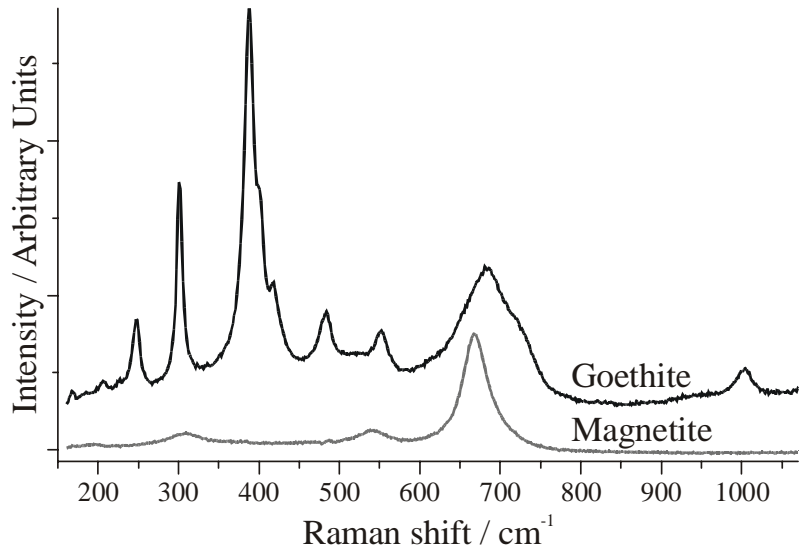

Figure 4. Comparison of the intensity of the spectra of the goethite and the magnetite, laser power $0.06 \mathrm{~mW}$, $1800 \mathrm{~s} \times 2$ accumulations

\section{RESULTS}

\section{Cross section analyses}

Cross-sections made on archaeological artefacts can be described as follow from the metal to the soil (Figure 5):

- The metallic substrate (M) containing various amounts of minor elements and also slag inclusions coming from reduction stage $\mathrm{e}^{15,35}$.

- A layer of corrosion products made of iron oxides, oxyhydroxides and/or carbonates. These phases are generally well crystallised and relatively compact. Thus this layer will be named "Dense Product Layer" (DPL). This DPL can contain internal markers (IM) as slag inclusions coming from the metallic substrate.

- A transition zone between the DPL and the non altered soil, containing both corrosion products and markers from the soil as quartz grain, considered as external markers. This zone will be called "transformed medium" (TM). The surface between the DPL and the TM corresponds to the old original surface (OS) of the object that has probably moved during the corrosion.

- The soil (S), where no corrosion products can be found. In the following, these abbreviations will always be used to describe the corrosion system.

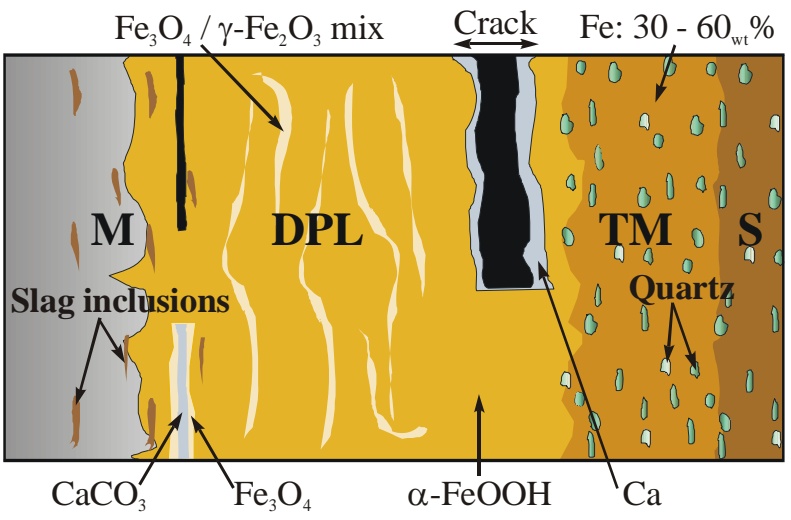

Figure 5. Main corrosion form observed on the different objects of the corpus

It has first been observed that all the iron cores are hypoeutectoid steels ${ }^{13}$. Carbon excepted, the main minor element detected is phosphorous, that can be present until 0.5 mass $\%$. Carbon and phosphorous are in the most case heterogeneously distributed. The iron substrate contain also slag inclusions composed mainly of iron silicates and oxides. These slag inclusions are numerous in most of the substrate and contribute to the structural heterogeneity of the metal. Metallic substrates are comparable from one site to another.

The investigations realised on the corrosion products concern mainly the DPL i.e., the scales that appear relatively dense and homogeneous directly in contact with the metal and do not contain any quartz grain. Considering the DPL, the 38 analysed objects coming from five different sites can be classified in two different types of corrosion forms.

The first one concerns the objects coming from the Cabaret, Avrilly and Montbaron sites and is schematised 
in Figure 5. It is the main corrosion form that is identified the objects of the corpus. The DPL are constituted by a phase that appears light dark under optical microscope. This phase is marbled by a fine light grey phase, which appears under the form of filaments. These filaments are numerous and constituted of magnetite and sometimes maghemite. The dark phase is identified as goethite. As an example, Figure 6 shows some Raman spectra of these different phases. Frequently some strips containing calcium are observed in the DPL. These phases are identified as calcite or mixed carbonate (calcite and siderite).

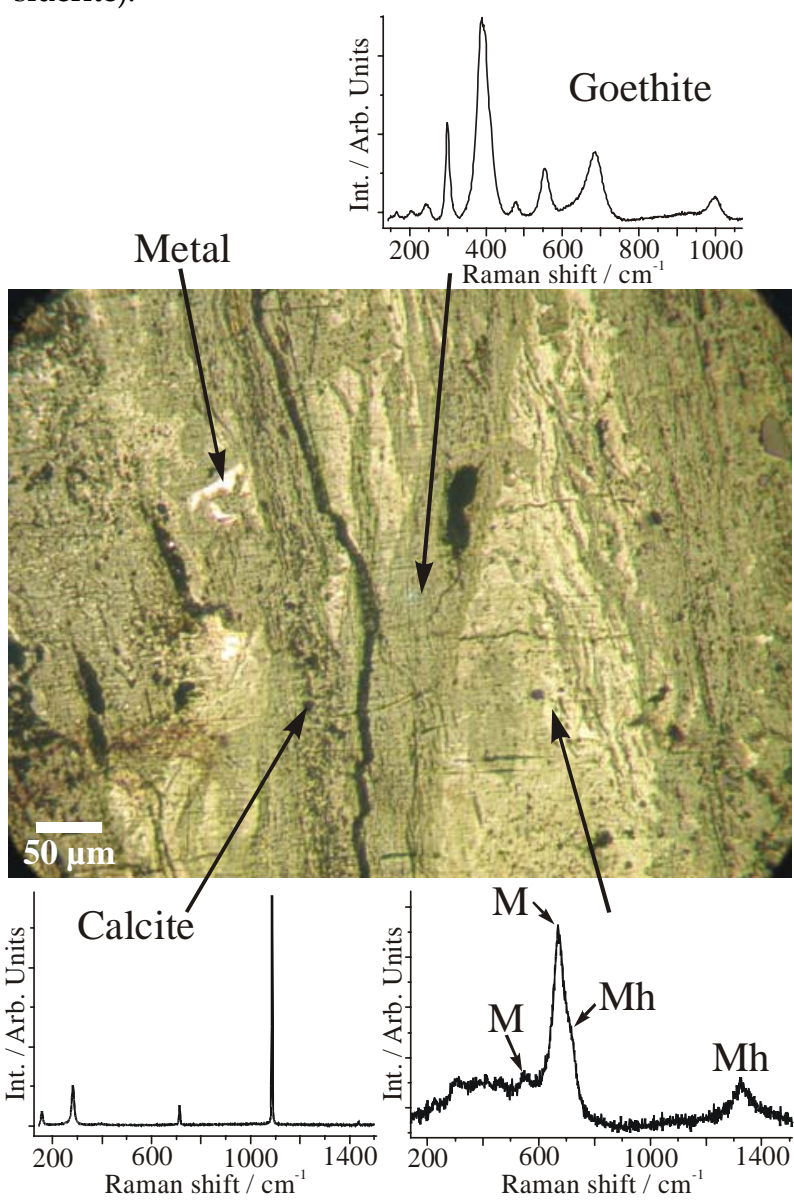

Figure 6. Morphology of the DPL with marbled aspect, optical micrography and Raman spectra of goethite, calcite and magnetite (M) with maghemite (Mh), sample Mont4, Montbaron site

The second type of corrosion form was only observed on the objects of the site of Glinet. As shown on the microphotograph of Figure 7, a layer composed of Ca-containing siderite is directly in contact with the metal. In these layers two types of fine strips appear regularly. The first one is grey light and is made of magnetite. The second type is composed of oxygen, iron, but also sulphur (until 17 mass \%). Because of its very small size, the structure of this strip could not be determined by microstructural characterisation. Finally, some calcite aggregates were also identified.

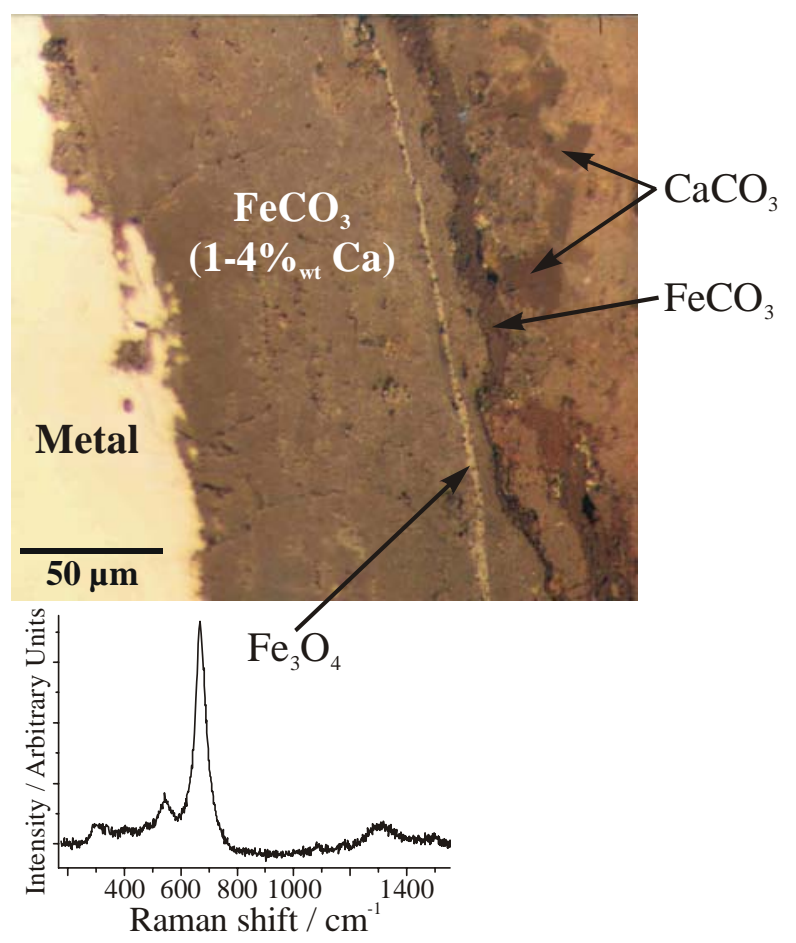

Figure 7. Typology of the DPL of the objects of Glinet, optical micrography and a Raman spectrum of the magnetite strip

It is interesting to note that weather by $\mu \mathrm{XRD}$ or by $\mu$ Raman it is more difficult to determine the structure of the phases constituting the TM. In this zone the only identified phases are goethite and haematite, but spectra show weak and broad peaks contrary to the DPL where peaks are well defined on the spectra. This fact could be linked to a different formation mechanism than in the DPL.

\section{Stratigraphic probe}

A nail from the Glinet site, previously analysed by the cross section approach was studied by stratigraphic probe. As for the previous analysis on cross sections, siderite, magnetite and calcite were detected by $\mu$ Raman: it is a similar corrosion form than those who was established on the cross sections.

A second object coming from the medieval site of Saint-Denis was studied by this approach. Figure 8 described the corrosion system that was found on this object, following the terminology developed by Bertholon $^{11,12}$ to designate the different strata. Magnetite (or maghemite) were identified in strata CP2.CP1e and CP3.CP1i on both sides of the limit of the original surface. Goethite $(\alpha-\mathrm{FeOOH})$ was also identified in stratum CP3.CP2i which is now the core material due to the complete alteration of the metallic iron. $\mu$ Raman analysis shows that the white material in CP3.D1i is a (Fe-Ca) carbonate which could have precipitated in previously formed cracks. As shown on the artefacts from Cabaret, Montbaron or Avrilly, it becomes more difficult to collect Raman spectra in the zone containing soil minerals, which seems to be less crystallised. The corrosion products on this sample shows a form that is very similar to the first described in the previous part 
(Figure 5): the corrosion products are composed mainly of well crystallised goethite and magnetite near the metal.

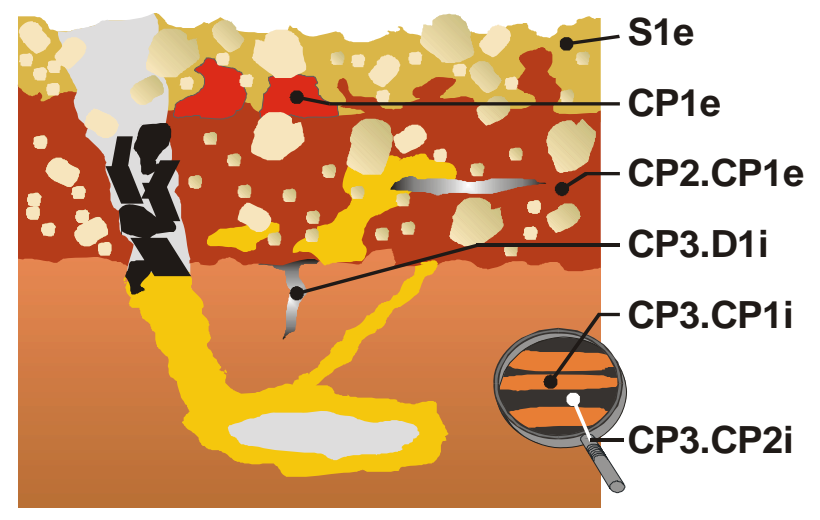

Figure 8. Corrosion form observed on the Saint Denis artefact after stratigraphic probing, examination and $\mu$ Raman analyses

\section{DISCUSSION}

On the objects of Glinet, it seems that the presence of siderite on one hand and of sulphur-containing phases on the other hand indicates that microbial corrosion has occurred. This hypothesis is reinforced by the fact that the zone where the objects were sampled is a waterlogged soil containing wood peaces that can provide organic matter. Meanwhile the presence of the magnetite strip in the siderite could be due to a change in the potential-pH conditions during the burial period.

The other corrosion form is the most common one characterised in this study. The presence of goethite in contact with the metal indicates that the burial conditions were always oxidant in the sites where such corrosion forms were found (Cabaret, Montbaron, Avrilly and Saint Denis). The presence of calcium-containing phases in the DPL of some of these objects shows that ions coming from the nearby environment can migrate into the corrosion products. This result is in agreement with the conclusion of Pons ${ }^{9}$ who has shown that the layer in contact with the metal is relatively porous. Considering the TM, analyses indicate that iron precipitates mainly as oxyhydroxides. Moreover the fact that theses phases are not well crystallised could indicate that the crystal grains have no sufficient time to grow. It could be due to the presence of the water solution of the soil which could render soluble the iron corrosion products, transport the iron species by diffusion or convection. These last could precipitate again in a more oxidant zone farther from the iron core. This is a hypothesis to explain the iron migration from the object into the environment.

It seems that the same typology is identified on the Saint Denis artefact on which only stratigraphic probing was performed. This result shows the possibility of appraising corroded objects with a non destructive analytical method when a previous corrosion form is established. This lead us to propose a general methodology, that could be used in conservation to study and understand the corrosion forms and conduct to identify different corrosion typologies (Figure 9):

1. Stratigraphic probing of a statistical number of artefacts using $\mu$ Raman to characterise the phases of the TM and DPL

2. If the identified corrosion form corresponds to a classified corrosion form, a diagnostic is possible, leading to the delimitation of the corrosion system and particularly of the original surface limit.

3. If the identified corrosion form does not correspond to a classified one then it is necessary to perform a complete characterisation of the system on cross sections and by using other methods as EDS, EPMA and $\mu$ XRD. This complete characterisation will lead to a new corrosion form and typology.
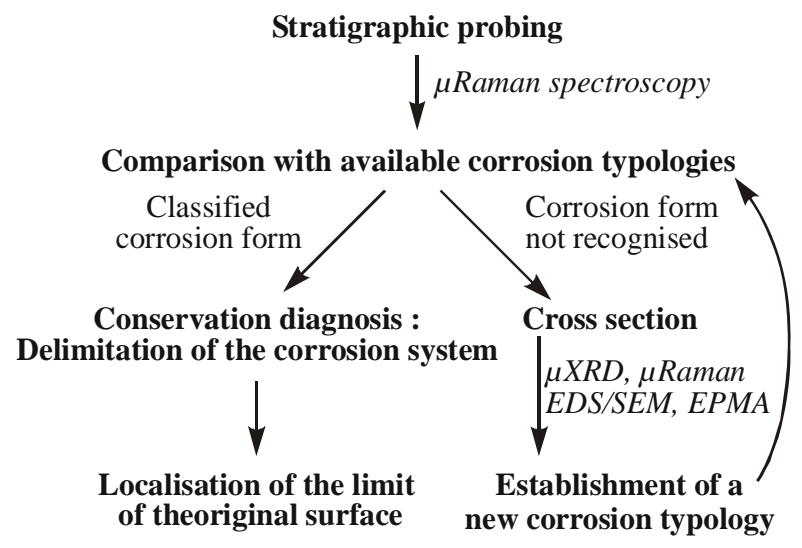

Figure 9. Analytical methodology to analyse the corrosion products of archaeological artefacts

\section{CONCLUSION}

The coupling between the results obtained by $\mu$ Raman and $\mu$ XRD allows us to ensure the identification of the corrosion products formed on about forty archaeological iron artefacts. It seems that the most frequent corrosion form observed on iron archaeological artefacts of the analysed corpus is formed mainly by goethite enclosing magnetite/maghemite strips. This form has been identified on objects coming from four sites with different soils composition. On these objects the migration of iron in the environment has been observed. An explanation of this phenomenon could be successive dissolution/precipitation of iron species transported by the solution of the soil.

Furthermore, it has been tested that when the corrosion typology is well establish, it will be possible to recognise corrosion forms on another artefacts only by performing a the stratigraphic approach, with the help of $\mu$ Raman. It will be then easier to locate the original surface on these artefacts and ensure a reliable restoration of them. This lead us to propose a methodology for further studies of archaeological artefacts in a conservation approach. 


\section{Acknowledgements}

The authors would like to thank the archaeologists to allow them to work and sample the objects that they entrust to us: Marie-Elise Gardel (Cabaret), Armelle Querrien (Montbaron), Bérengère Lecain (Avrilly), Danielle Arribet (Glinet).

This study was supported by ANDRA (French National Agency for Nuclear Waste Management) and the GDR 2114 of CNRS "Physico-Chimie des Matériaux du Patrimoine Culturel" (CHIMART)

\section{REFERENCES}

1. Accary A, Haijtink B. Actes du colloque "Journées de paleométallurgie" 1983; 323

2. Miller B, Chapman N. Radwaste magazine, Jan 1995; 32.

3. Johnson AB, Francis B. Durability of metals from Archaeological objects, metal meteorites and native metals, (1980). in A. Accary and B. Miller [1, 2]

4. Galliano F, Gerwin W, Menzel K. Metal 98 Conference on Metals Conservation, Draguignan-Figanières, France 1998; 87.

5. Soerensen B, Gregory D. Metal 98 conference on metals conservation, Draguignan-Figanières, France 1998; 94.

6. Gerwin W, Sharff W, Baumhauer R. Metal 98 conference on metals conservation, Draguignan-Figanières, France 1998; 100.

7. Angelini E, Barberis E, Bianco P, Rosalbino F, Ruatta L. Metal 98 conference on metals conservation, DraguignanFiganières, France 1998; 106.

8. Fell V, Ward M. Metal 98 conference on metals conservation, Draguignan-Figanières, France 1998; 111.

9. Pons E. PhD Thesis, Corrosion à long terme $d u$ fer et des aciers non ou faiblement alliés dans les sols à dominante argileuse - Caractérisation Physico-chimique et étude électrochimique d'analogues archéologiques, Université de Technologie de Compiègne France, 2002

10. Pons E, Uran L, Joiret S, Hugot-Le Goff A, Lemaitre C, David D. Prediction of long term corrosion behaviour in Nuclear Wastes System, Cadarache, France, EFC series 2003; 36, 334-345.

11. Bertholon R, Relier C. La conservation en archéologie, Méthodes et pratique de la conservation-restauration des vestiges archéologiques, Masson, Paris, Milan, Barcelone, Mexico 1990: 163-221.

12. Bertholon R. PhD Thesis, La limite de la surface d'origine des objets métalliques archéologiques, Caractérisation, localisation et approche des mécanismes de conservation, Université Paris I-Sorbonne, 2000: 419.

13. Neff D, Dillmann P, Béranger G. Prediction of long term corrosion behaviour in Nuclear Wastes System, Cadarache, France, EFC series 2003; 36, 295 - 315.

14. Dillmann P, Neff D, Mazaudier F, Hoerle S, Chevallier P, Béranger G. J. Phys IV France, 2002: 393-408.

15. Dillmann P, Populus $P$, Chevallier P, Fluzin P, Béranger G, Firsov A. Journal of Trace and Microprobe Techniques 1997; 15: 251

16. Dillmann P, Balasubramaniam R, Béranger G. Corrosion Science 2002; 44: 2231.

17. Beattie IR, Gilson TR. Journal of the Chemical Society (A) 1970: 980-986.

18. Thibeau RJ, Brown CW, Heidersbach RH. Applied Spectroscopy 1978; 32: 532-535.

19. Nauer G, Strecha P, Brinda-Konopik N, Liptay G. Journal of Thermal Analysis 1985; 30: 813-830.
20. Ohtsuka T, Kubo K, Sato N. Corrosion-NACE 1986; 42: 476481.

21. Boucherit N, Delichere P, Joiret S, Hugot-Le Goff A. Material Science Forum 1989; 44-45: 51-62.

22. Dünnwald J, Otto A. Corrosion Science 1989; 29: 1167-1176.

23. Boucherit N, Hugot-Le Goff A, Joiret S. Corrosion Science 1991; 32: 497-507.

24. Thierry D, Persson D, Leygraf C, Boucherit N, Hugot-Le Goff A. Corrosion Science 1991; 32: 273-284.

25. De Faria DLA, Venâncio S, De Oliveira MT. Journal of Raman Spectroscopy 1997; 28: 873-878.

26. Oh SJ, Cook DC, Townsend HE. Hyperfine Interactions 1998; 112: 59-65.

27. Bersani D, Lottici PP, Montenero A. Journal of Raman Spectroscopy 1999; 30: 355-360.

28. Sousa MH, Tourinho FA, Rubim JC. Journal of Raman Spectroscopy 2000; 31: 185-191.

29. Simpson LJ, Melendres CA. Journal of the Electrochemical Society 1996; 143: 2146-2152.

30. Gabrielli C, Jaouhari R, Joiret S, Maurin G. Journal of Raman Spectroscopy 2000; 31: 497-501.

31. Legrand L, Sagon G, Lecomte S, Chausse A, Messina R. Corrosion Science 2001; 43: 1739-1749.

32. Savoye S, Legrand L, Sagon S, Lecomte S, Chausse A, Messina R, Toulhoat P. Corrosion Science 2001; 43: 2049-2064.

33. Bernard MC, Duval S, Joiret S, Keddam M, Ropital F, Takenouti H. Progress in Organic Coatings 2002; 45: 399-404.

34. Schwertmann U, Cornell R. The Iron Oxides, Wiley VCH edition, $2^{\text {nd }}$ edition, Weinheim, 2003.

35. Dillmann P, Fluzin P, Chevallier P. British Archaeological Reports International Series 2002; 1043: 32. 